Thomas L. Marchioro, David T. Rowlands, Jr., David Pifkind

William R. Waddell, Thomas E. Starzl

Hugh Fudenberg

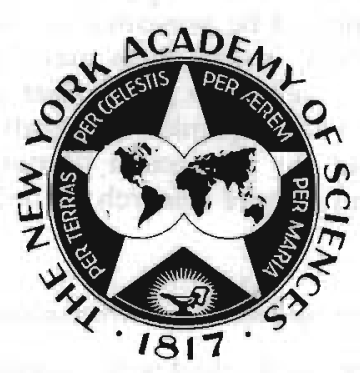

Reprinted from

ANNALS OF THE NEW YORK ACADEMY OF SCIENCES

Volume 120, Article 1, Pages 626-651

November 30, 1964 


\title{
SPLENIC HOMOTRANSPLANTATION*
}

\author{
Thomas L. Marchioro, David T. Rowlands, Jr., David Rifkind \\ William R. Waddell, Thomas E. Starzl† \\ Departments of Surgery, Pathology, and Medicine, University of Colorado Medical Center \\ and Veterans Administration Hospital, Denver, Colo. \\ Hugh Fudenberg \\ Department of Medicine, University of California Medical Center \\ San Francisco, Calit.
}

During the past 12 months, five clinical whole-organ splenic homotransplantations have been carried out with the objective of providing active immunologic tissue for the recipient patients. In one case with hypogammaglobulinemia, it was hoped that the transplanted tissue would alleviate a state of immunologic deficiency. In the other four, all of whom had terminal malignancies, the purpose was to superimpose a state of altered immunologic reactivity upon the host in - the hope of thereby suppressing the inexorable growth of the neoplasms.

As will be described, these procedures can now be judged in each instance to have been without benefit. Nevertheless, full documentation of the cases seems justified not only because of the many implications of transplantation of immunologically competent tissue, but also because of the potentially important observations made during the care of these patients.

In addition, a full account will be presented of the supporting canine studies of splenic homotransplantation, inasmuch as many of the principles of clinical therapy and investigation derived from prior observations in the dog. The fact that it is possible to obtain viable splenic homografts in the dog for as long as two-thirds of a year without the production of runt disease or other harmful effects may have application in future research on bone marrow, other lymphoid, or hepatic homografts.

\section{Canine Splenic Homotransplantation}

All splenic transplants were performed with a method shown in Frgures 1 and 2. Donors were selected of approximately the same size as the recipient, cooled to $30-32^{\circ} \mathrm{C}$., and systemically heparinized $(2 \mathrm{mg} . / \mathrm{kg}$.). The spleens were revascularized from the pelvic vessels (FIGURE 2 ) after rotating the organs end-forend and reversing the anteroposterior relationships (FIGURE 2). By doing this, the eccentrically placed hilum was brought into convenient relation to the blood supply, allowing the long inferior pole to lie comfortably in the left paravertebral gutter without fixation. Physiologically, the preparation differs from normal in that the splenic venous drainage is into systemic rather than portal channels. For controls, autografts were performed.

The protocol for splenic homotransplantation is depicted schematically in FIGURE 3. Briefly, experiments were done in which untreated hosts (FIGURE 3A), hosts pretreated with irradiation (FIGURE 3B), and hosts treated with azathioprine (FIGURE 3C) were used.

Splenic autografts. Seven dogs received autografts using essentially the same technique and were either sacrificed at nine days (three animals) or followed

* Aided by Grants A-6283, A 6344, HE 07735, AM 07772, AI 04152, OG 27, and H 5997 from the.U. S. Public Health Service.

$\dagger$ Markle Scholar. 


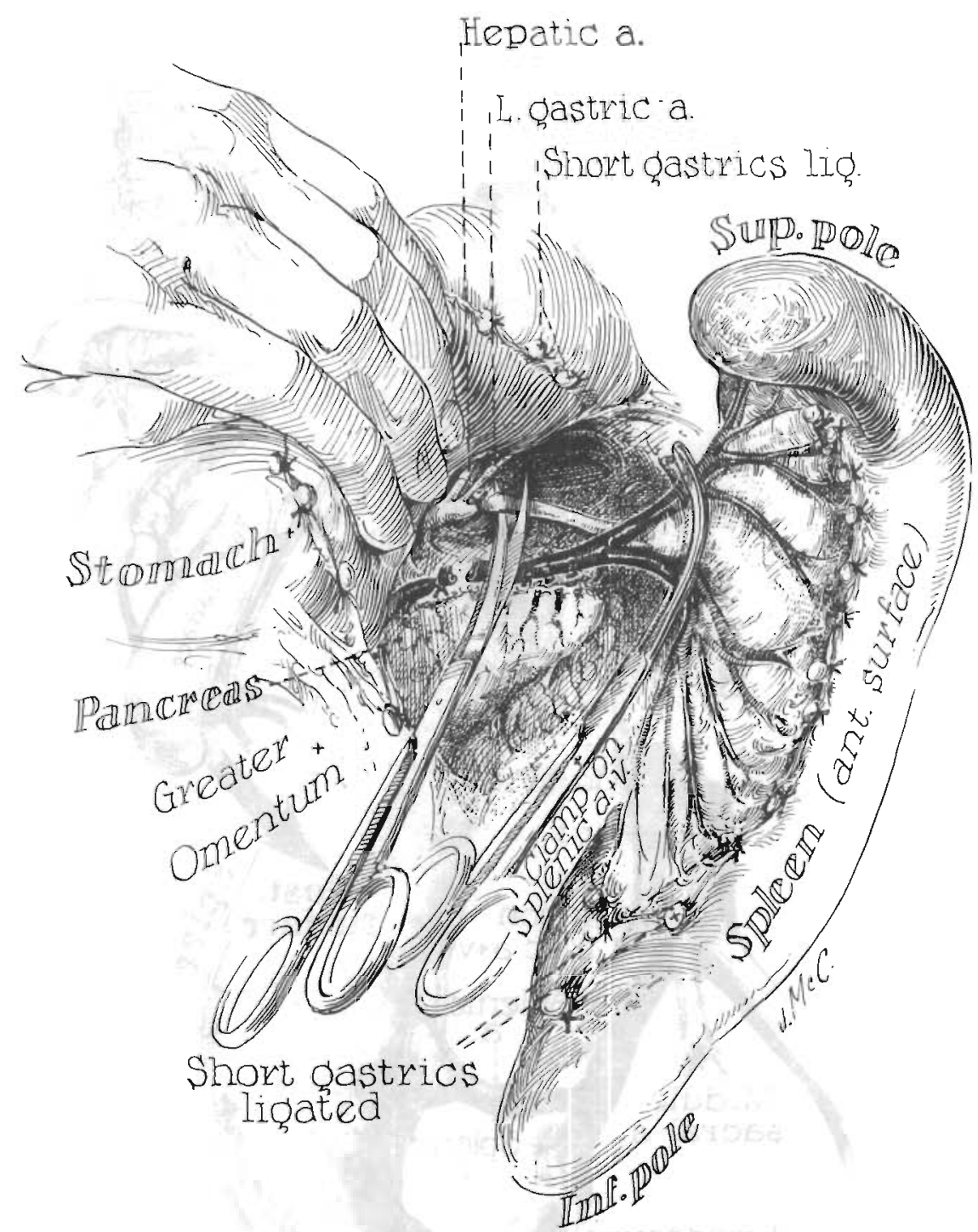

FigurE 1. Technique of canine splenectomy for transplantation. The short gastric vessels are ligated and divided and the main splenic artery and vein skeletonized.

from eight to ten and one-half months (four animals). Transfusions were not employed in any case. The average hematocrit in the three animals sacrificed after nine days dropped from 46 per cent to 32 per cent. Red cell survival studies were performed on these three dogs, each animal serving as its own control. Before surgery, $10 \mathrm{ml}$. of autogenous blood was drawn from a foreleg vein, mixed with $4 \mathrm{ml}$. of ACD solution containing five microcuries of $\mathrm{Cr}^{51}$ per $\mathrm{kg}$. body weight, and incubated for 60 minutes. Specific activity of the $\mathrm{Cr}^{51}$ was 100 milli- 


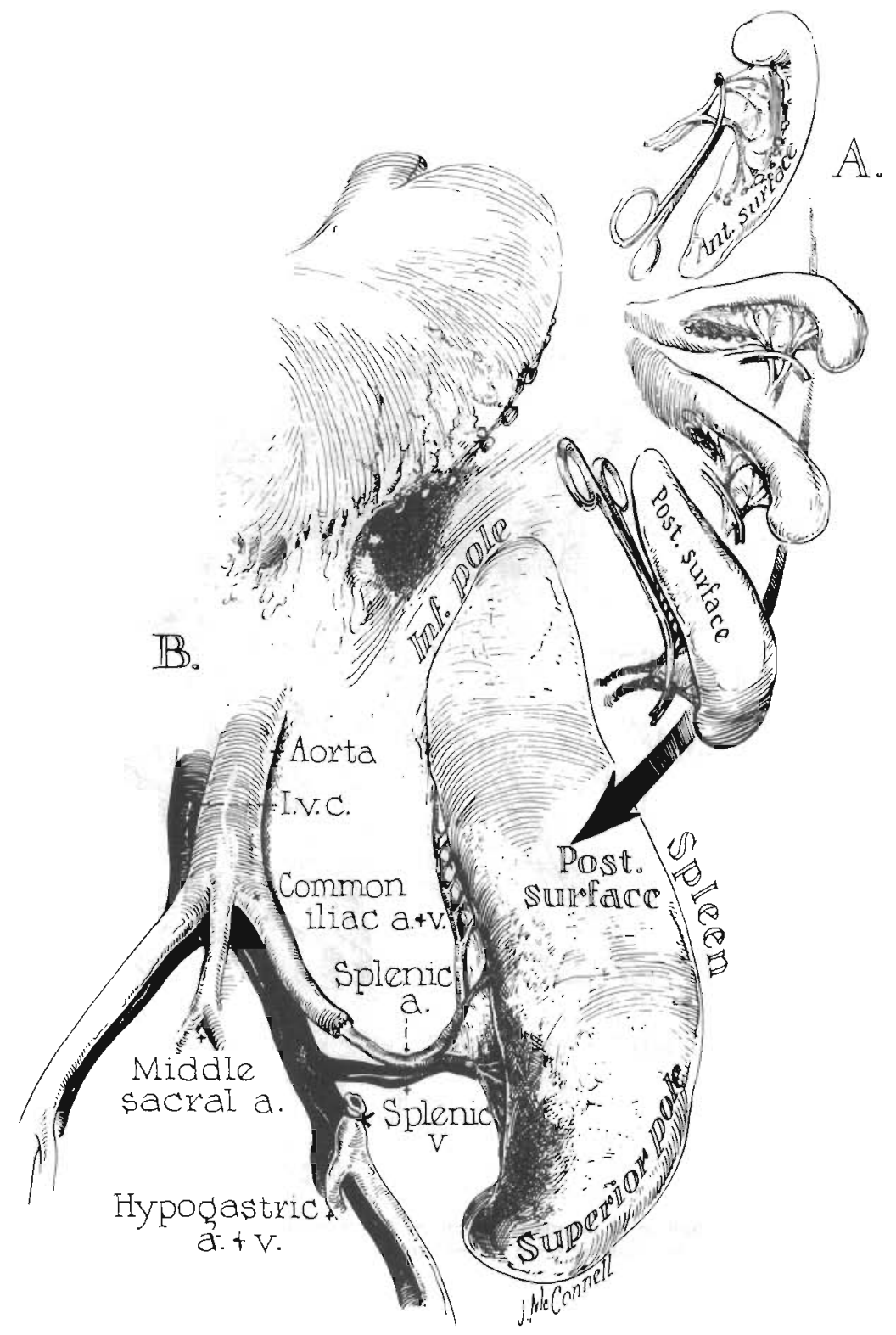

FIGURe 2. Technique for revascularization of a canine splenic homograft. Note the eccentric relationship of the vascular pedicle to the body of the spleen. Rotation of the spleen end-for-end permits attachment of the splenic vessels to the common iliac artery and vein so that the spleen lies comfortably in the left paravertebral gutter. 

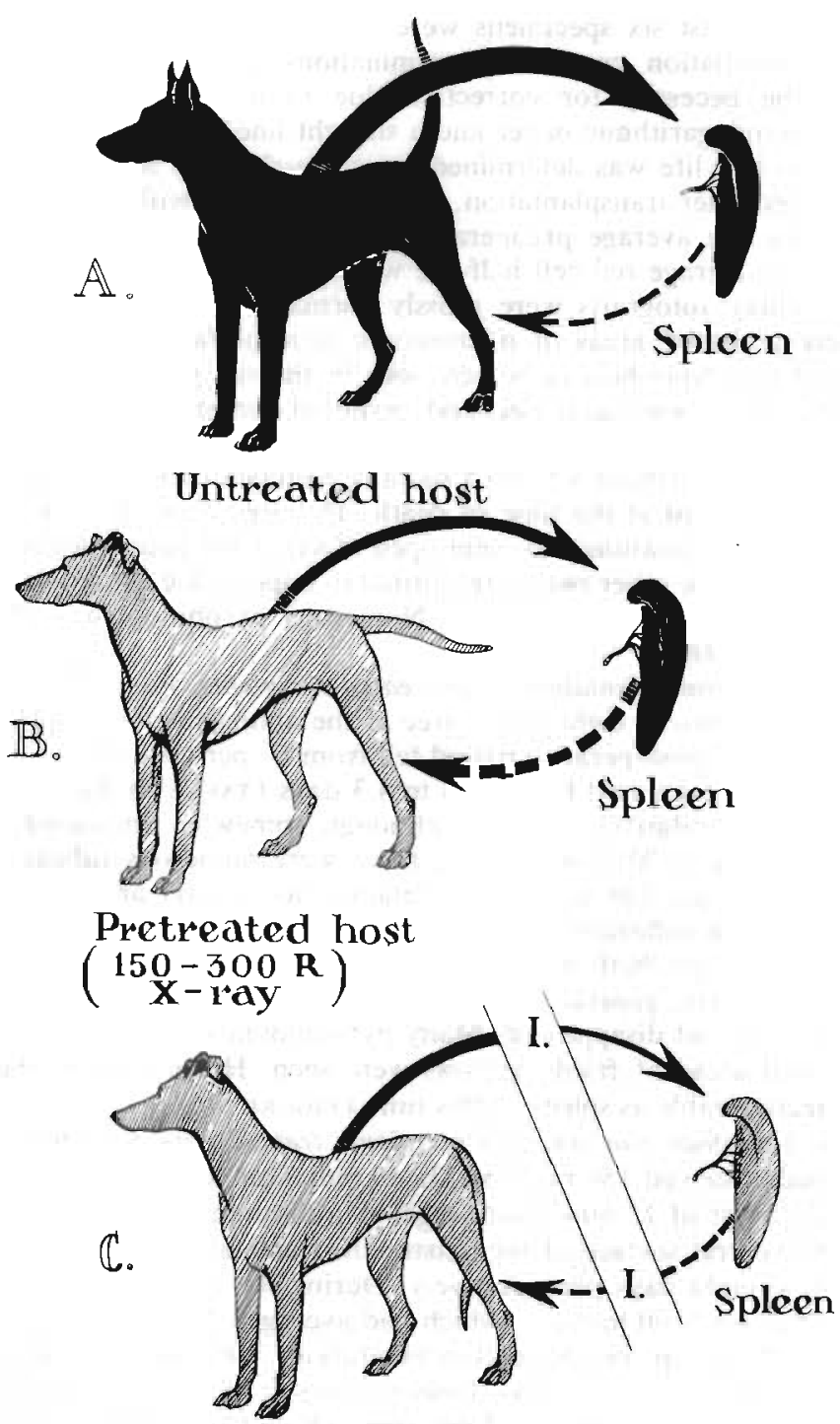

Imuran treatment

Figure 3. Schematic outline of protocol used for splenic homografts in dogs. (A) Splenic homografts to untreated hosts. $(B)$ Splenic homografts to host pretreated with 150 to 300 rads total-body irradiation. (C) Splenic homograft to hosts treated with azathioprine started on the day of transplantation and continued thereafter. 
curies per $\mathrm{mg}$. of $\mathrm{Cr}$ or more. Efficiency of red cell uptake of the $\mathrm{Cr}^{51}$ was 90 per cent or more. Ten $\mathrm{ml}$. of the incubated mixture were then reinjected, keeping the remaining $4 \mathrm{ml}$. for baseline studies. Blood samples were taken every 24 hours until at least six specimens were obtained. Samples were analyzed in a well-type scintillation counter. Determinations were done simultaneously to eliminate the necessity for correction due to decay. Values obtained were plotted on semilogarithmic paper and a straight line drawn to the best visual fit. The red cell half-life was determined from the slope of this line. These studies were repeated after transplantation. In the three dogs with autografts sacrificed at nine days, the average preoperative red cell half-life was 10.4 days. After operation the average red cell half-life was 14.2 days (TABLE 1 ).

The nine-day autografts were grossly normal with patent vessels. However, there were scattered areas of microscopic subcapsular hemorrhage. Moderate numbers of pyroninophilic cells were seen in the red pulp. The white pulp was identifiable but it was decreased and germinal centers were frequently absent (FIGURE 4a).

Four animals sacrificed 8 to 10.5 months postoperatively had a mean hematocrit of 41.5 per cent at the time of death. The mean red cell half-life was 13.6 days. All vascular anastomoses were open. Two of the four spleens were grossly shrunken, while the other two were normal in appearance. Microscopically, welldeveloped white pulp was present. Numerous pyroninophilic cells were still present (FIGURE 4b).

Splenic homotransplantation to untreated recipients. Four dogs were studied, with survival of two to eight days, three of the animals being sacrificed. Average hematocrit in the postoperative period fell from 50 per cent to 37.5 per cent. The red cell half-life decreased from 12.4 to 4.3 days (TABLE 1). Grossly, the homografts appeared relatively normal, although somewhat increased in size. All vessels were patent. Microscopically, there were numerous subcapsular hemorrhages at two days. The white pulp retained its general architecture, although there was diffuse infiltration of polymorphonuclear leukocytes. Pyroninophilic cells were numerous, both in the white and red pulp (FIGURE $5 a$ ).

After eight days, general hemorrhage throughout the specimen was present. The white pulp had disappeared. Many pyroninophilic cells remained in the red pulp. Several areas of frank necrosis were seen. Histologically, the tissue was scarcely recognizable as spleen at this time (FIGURE $5 b$ ).

Splenic homotransplantation to recipients treated with total-body irradiation. Four animals received 150 rads total-body radiation $\left(\mathrm{Co}^{60}\right.$ source unfiltered, with a half value layer of $12 \mathrm{~mm}$. lead, target skin distance, $95 \mathrm{~cm}$; entire dose delivered to the ventral surface of the outstretched animal). Irradiation was given in a single dose eight days preoperatively. During the interval between irradiation and operation, red cell half-life, which had averaged 14 days, dropped slightly to 13.7 days. After splenic homotransplantation, the average red cell half-life dropped precipitately to 5.7 days. Postoperatively, the mean hematocrit fell from 46.5 per cent to an average of 32 per cent. These four animals lived for four to seven days, one animal dying of a ruptured venous anastomosis at four days, and the other three being sacrificed. Grossly, the spleens appeared to be normal. Histologically, the tissues were comparable to that previously described in the untreated animals. There was extensive intraparenchymal hemorrhage and necrosis, and essentially complete depletion of the white pulp (FIGURE 6).

Four dogs were treated with 300 rads total-body іrradiation one day before splenic homotransplantation. The animals lived for five to seven days after opera- 


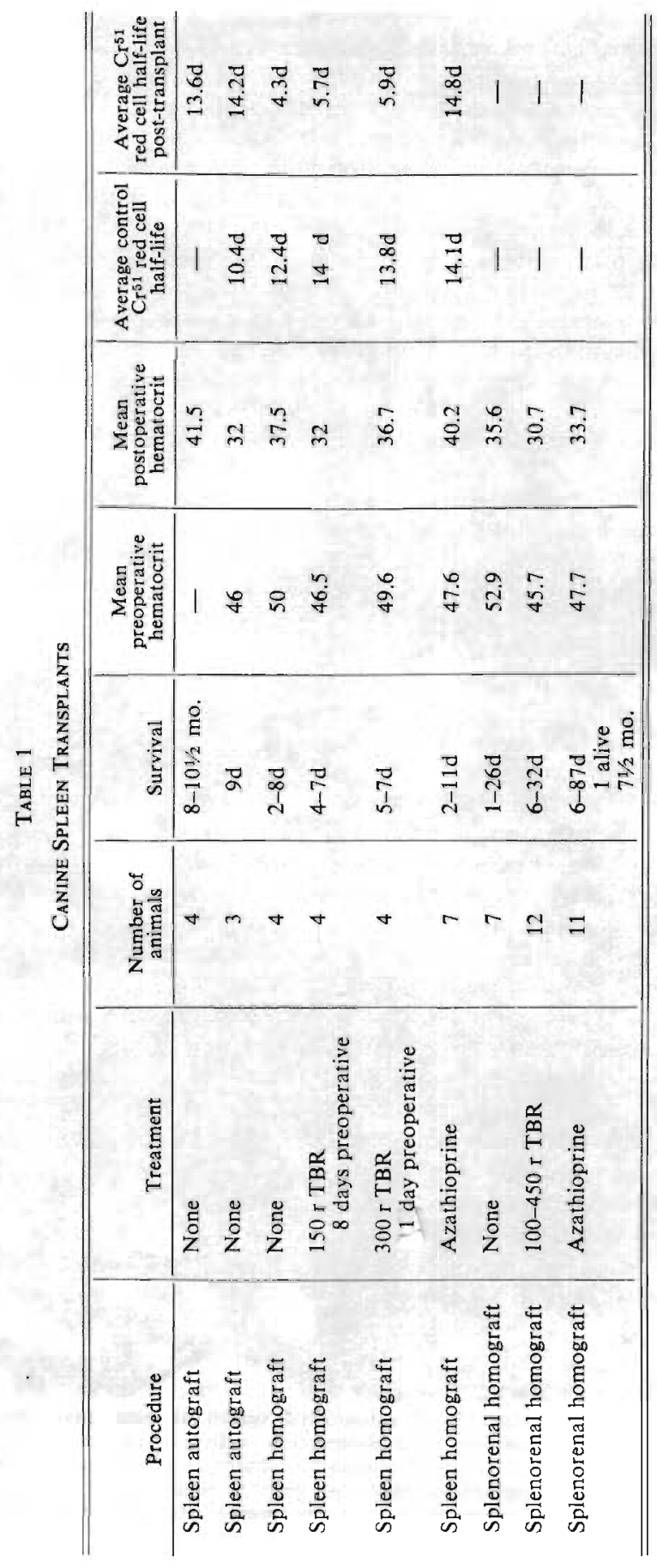




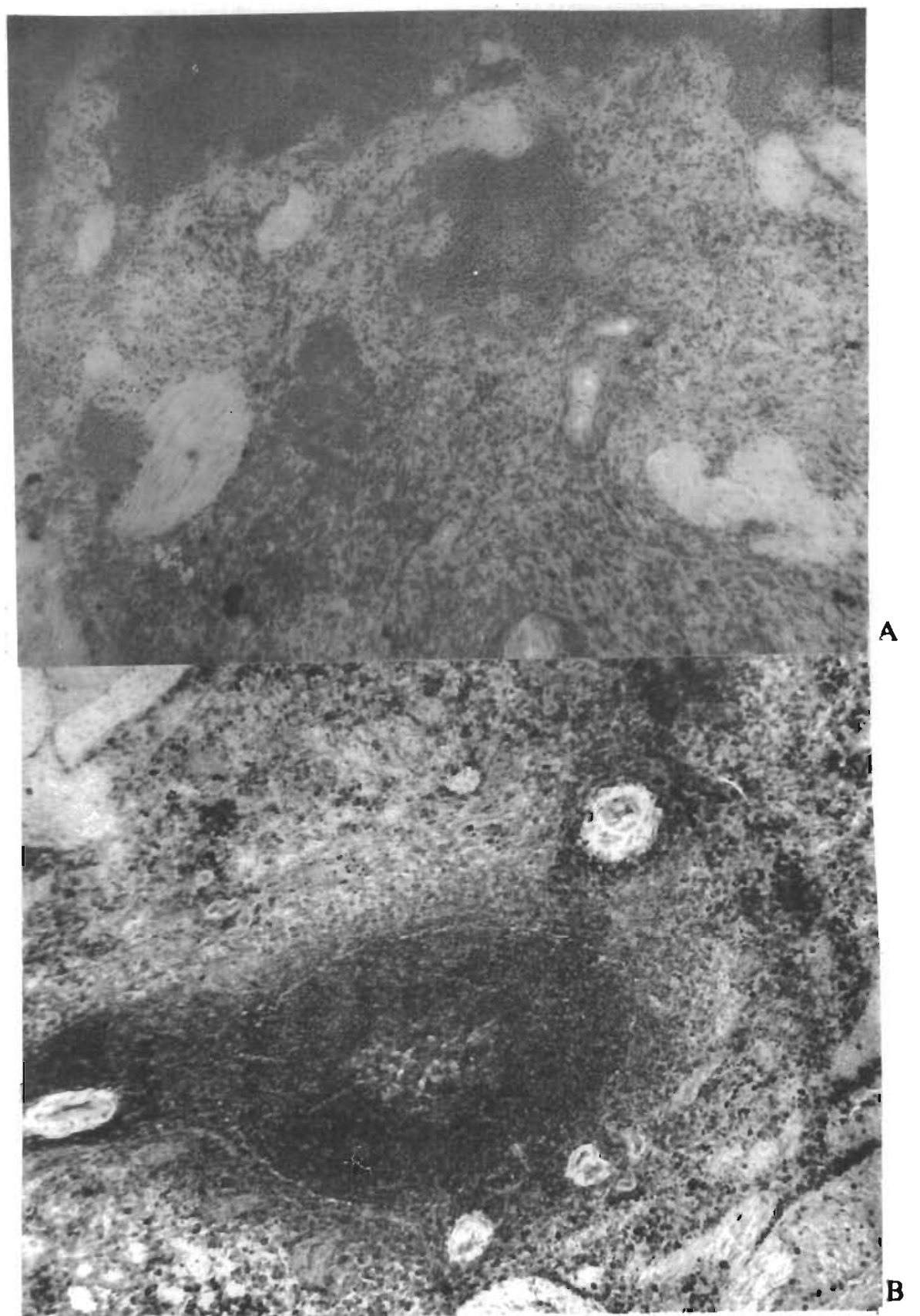

Figure $4 a$. Photomicrograph of autografted spleen at nine days. Note the scattered hemorrhage. Moderate numbers of pyroninophilic cells are present in the red pulp. The white pulp is decreased and germinal centers are absent (methyl-green-pyronin stain, $X 80$ ).

FIGURE $4 b$. Photomicrograph of splenic autograft at eight months. Note the well-developed white pulp. Numerous pyroninophilic cells are present throughout (methyl-green-pyronine stain, $\times 80$ ). 

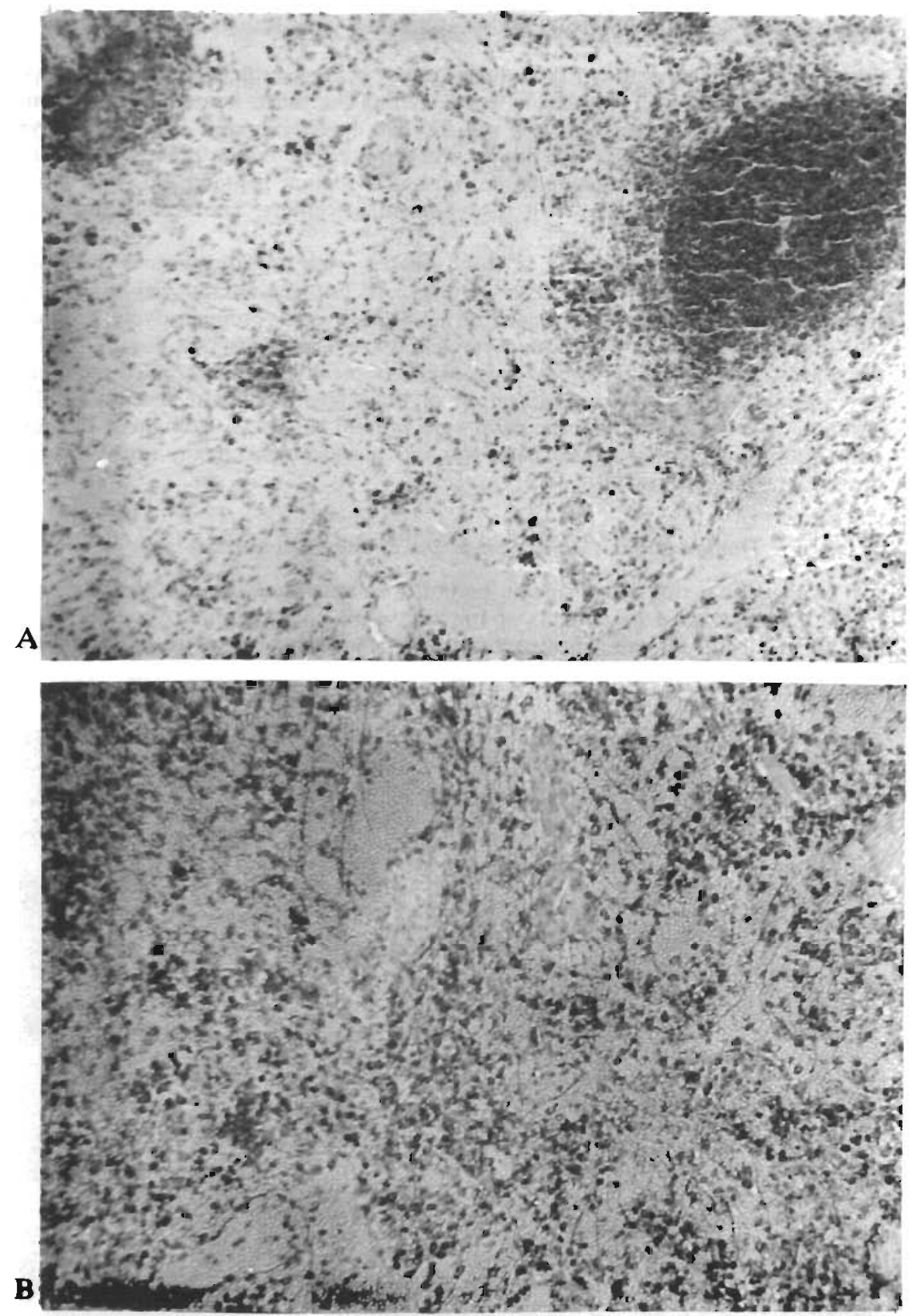

Figure 5a. Photomicrograph of untreated splenic homograft at two days. The whto pulp retains its general architecture. Numerous pyroninophilic cells are seen in both white and red pulp (methyl-green-pyronine stain, $\times 80$ ).

FIGURE $5 b$. Untreated splenic homograft at eight days.. Hemorrhage is generalized throughout the specimen and the white pulp has disappeared. Many pyroninophilic cells are seen in the red pulp (methyl-green-pyronine stain, $\times 80$ ). 
tion, three dying spontaneously and the fourth being sacrificed. The spleens appeared normal grossly. All vessels were patent. The mean hematocrit fell from 49.6 per cent to 36.7 per cent. Red cell survival decreased from 13.8 to 5.9 days (TABLE 1). Histologically, the organs were somewhat better preserved. There was congestion and mild to moderate intraparenchymal hemorrhage. The white pulp was partially preserved with absent germinal centers. The architecture was recognizable as spleen.

Splenic homotransplantation in dogs treated with azathioprine. Seven dogs were studied with survival of 2 to 11 days. All but one animal was sacrificed. Mean hematocrit fell from 47.6 per cent to 40.2 per cent. Preoperatively, red cell half-life averaged 14.1 days. Postoperatively, the average was 14.8 days. Grossly, the spleens were normal in appearance. Microscopically, they resembled the nineday autografts. There was preservation of the white pulp with absence of the germinal centers. Pyroninophilic cells were present in sheets throughout the red pulp. Intraparenchymal hemorrhage was less marked than in any group except the autografts (FIGURE 7).

\section{Double-Organ Canine Spleen and Kidney Homotransplants}

The preceding studies on splenic homotransplantation were rendered difficult by the fact that good parameters of function were not available. Accordingly, a second group of animals were studied in which double-organ transplants were

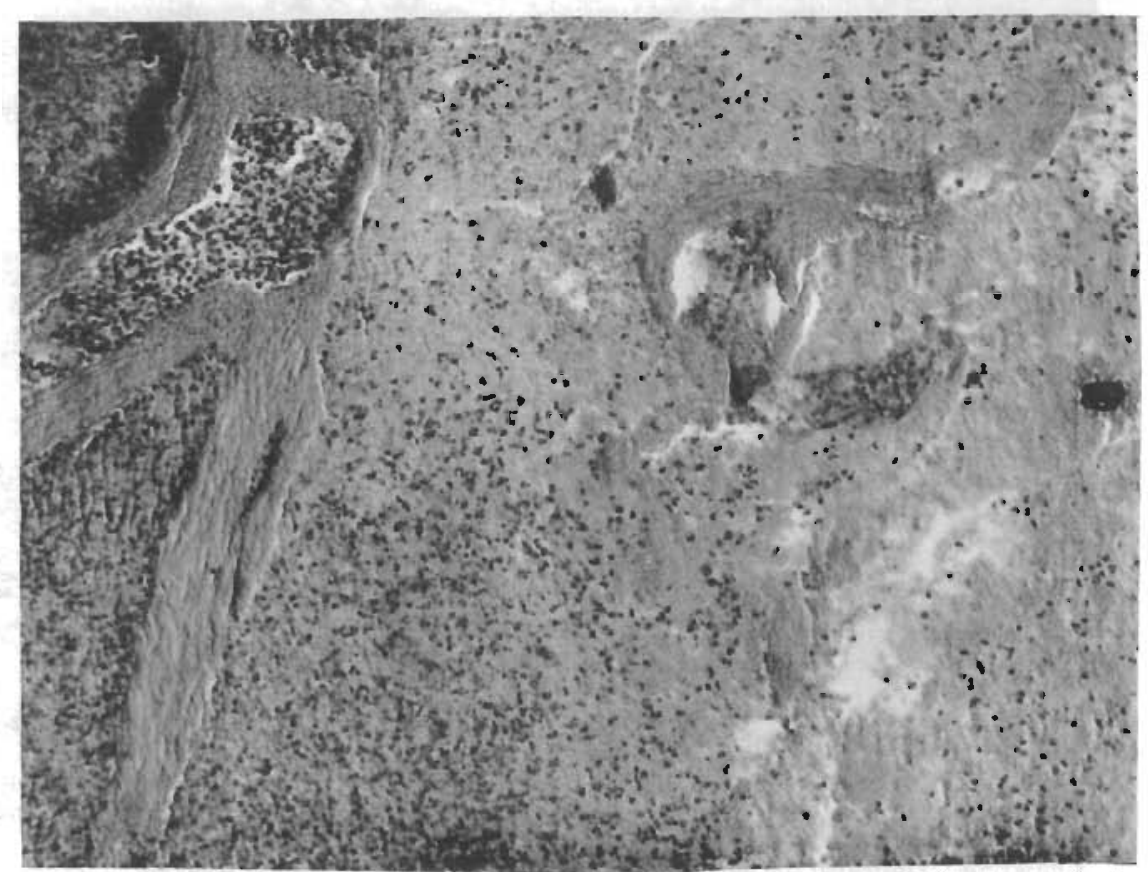

Figure 6. Splenic homograft at seven days from host pretreated with 150 rads total-body irradiation. The white pulp is depleted. Many polymorphonuclear leukocytes are present among areas of hemorrhage and frank necrosis (hematoxyline and eosin, $\times 80$ ). 


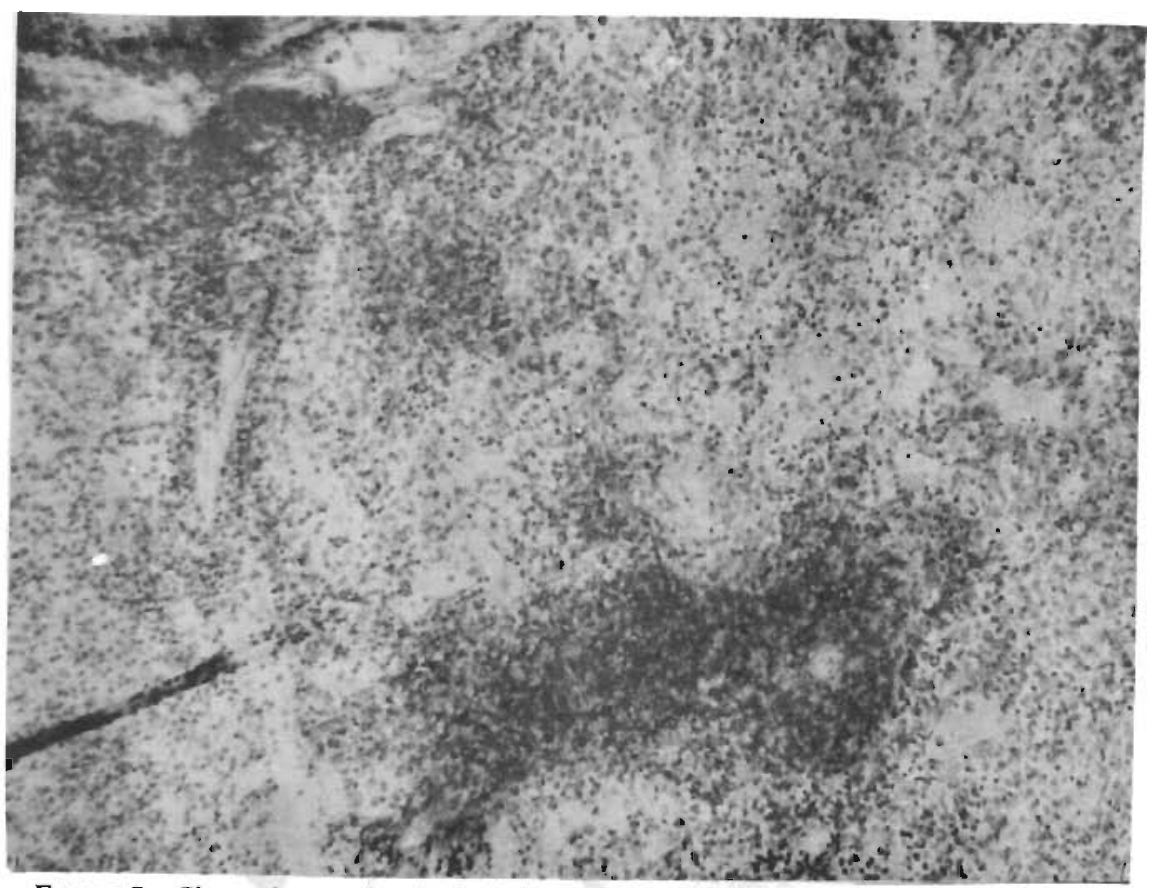

Figure 7. Photomicrograph of splenic homograft at 11 days from host treated with azathioprine. Note preservation of white pulp with absence of germinal centers. Pyroninophilic cells occur in sheets throughout the red pulp (methyl-green-pyronine stain, $\times 80$ ).

performed, the spleen being placed on the left side as previously described and a kidney homograft from the same donor being connected to the right pelvic vessels. Urinary drainage was provided by ureteroneocystostomy. The recipient animals had concomitant bilateral nephrectomy, so that the renal function could be construed as an indicator of the fate of both homografted organs.

The protocol employed is depicted schematically in FIGURE 8 . The groups included those not receiving any therapy (FIGURE $8 \mathrm{~B}$ ), those treated with preoperative irradiation (FIGURE 8C), and those treated with azathioprine (FIGURE 8D).

Double-organ homotransplants in untreated recipients. Seven dogs were in the untreated group. Survival ranged from 1 to 26 days. Three animals died in the immediate postoperative period from pneumonia. In the other four, mean survival averaged 20 days. This compares with a mean survival of $10.8 \pm 2.75$ (SD) days in 21 control animals receiving renal homografts alone. The potentiated survival of the kidney, when transplanted in conjunction with whole-organ spleens, was previously reported by Kountz ${ }^{1}$ and his associates. No red cell survival studies were conducted. Mean hematocrit fell from 52.9 per cent to 35.6 per cent, despite the fact that in this group of dogs, numerous small transfusions were given as indicated in contrast to the practice in the preceding section. All the animals died spontaneously, none being sacrificed. Grossly, four of the spleens had a normal contour, the others either being greatly enlarged or shrunken. In two additional animals, not included in the seven dogs, double-organ transplants 


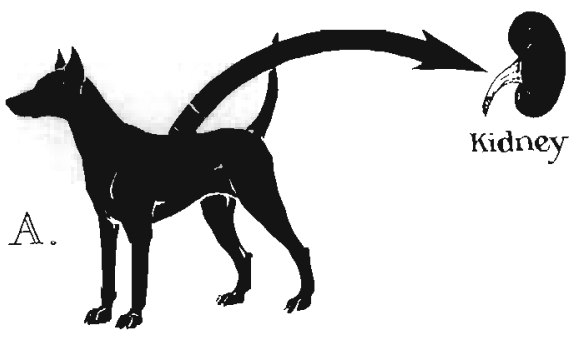

Untreated host
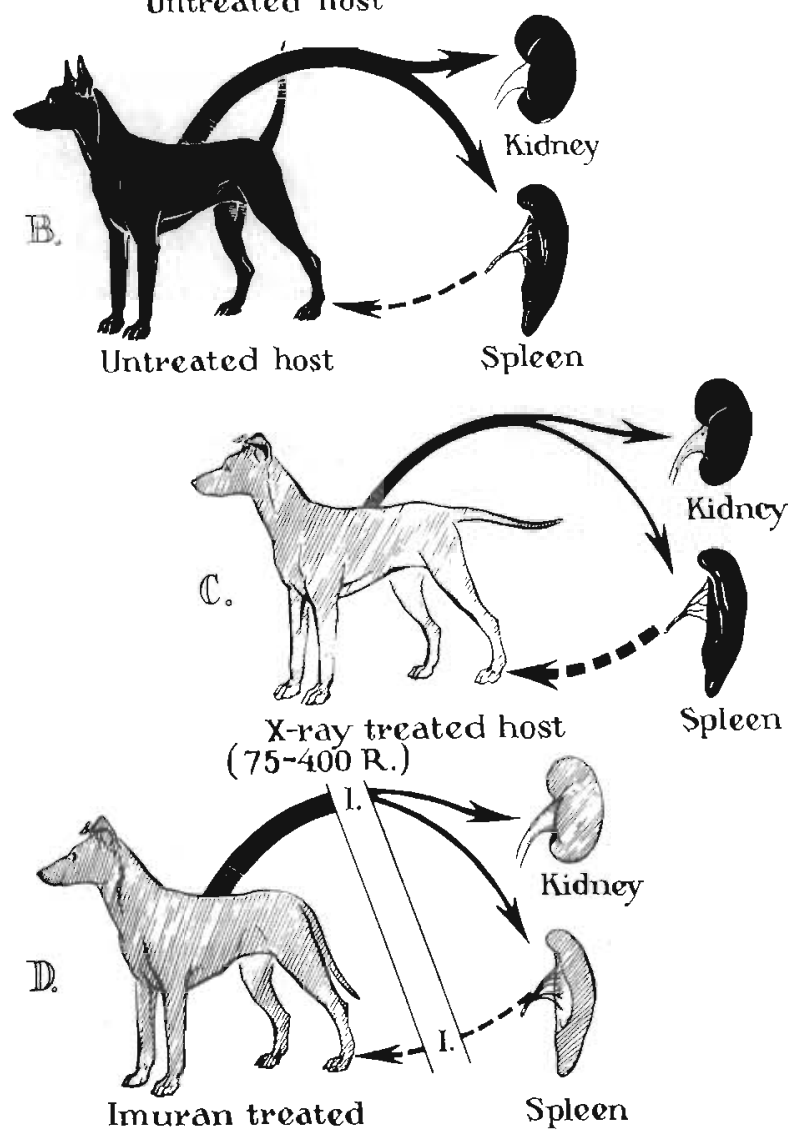

Figure 8. Protocol employed for the simultaneous splenic and renal homotransplants. (A) Control dogs receiving renal homografts only. (B) Control animals receiving concomitant renal and splenic homografts without therapy. (C) X-ray treated hosts who received simultaneous renal and splenic homografts. $(D)$ Combined homografts to hosts treated with azathioprine beginning at operation and continued indefinitely thereafter. 
were done and the animals sacrificed after two days in order to obtain specimens of the spleen. In the latter animals, the spleens were grossiy normal.

Histologically, the presence of the renal homograft appeared to exert no influence on the microscopic changes in the spleen. After one to two day's, the white pulp was still present, but there were numerous subcapsular hemorrhages. Sheets of pyroninophilic cells were present throughout the organ. After 10 days the histologic appearance was one of extensive necrosis, the splenic architecture being essentially unrecognizable. The degree of destruction to the kidney was far less extensive than that in the spleen in those animals living for 10 days or longer. The renal parenchyma was the site of focal round cell infiltration, but the kidney architecture was well-preserved. Functionally, all animals were uremic after five days, but large urinary outputs continued in some dogs for as long as 25 days after operation. There appeared, therefore, to be a more severe injury to the splenic than the renal homograft.

Double-organ homotransplants to dogs treated with preoperative irradiation. One hundred to 450 rads total-body irradiation was given to 12 animals. In most cases, the irradiation was given in divided doses. The animal lived for 6 to 32 days after operation. Red cell survival studies were not obtained. Frequent transfusions were required postoperatively, rapid drops in hematocrit being observed in each animal. Hemolysis was noted in the serum of three-fourths of the animals. Despite transfusions, the mean hematocrit fell from 45.7 per cent to 30.7 per cent.

Renal function was distinctly inferior to that observed in untreated animals (see previous section). Five of the animals became anuric within two days after operation, and uremia was fulminating in all but one dog, which survived for 32 days. At autopsy, the kidneys were the site of a hemorrhagic process in half the animals, the organs having a gross deep purple hue. The spleens varied in size, some being enlarged and others shrunken. Microscopically, severe intrarenal hemorrhage was common, especialiy at the corticomedullary junction. There was invariable evidence of extensive mononuclear cellular infiltrate throughout the renal parenchyma. The spleens were histologically comparable to those studied in the untreated group described above. There was early congestion and hemorrhage, and rapid disappearance of white pulp with the characteristic later necrosis. There appeared to have been no protection of the splenic homograft afforded by the irradiation and, indeed, the destructive process appeared to have been accelerated.

Double-organ homotransplants to recipients treated with azathioprine. Eleven dogs were studied. Azathioprine was begun on the day of or the day preceding operation. Survival was six days to seven and one-half months, one of the animals being still alive. No red cell survival studies were obtained. Within the first month, hematocrits dropped from 47.7 per cent to 33.7 per cent, but in the animals surviving beyond this time, further anemia was not noted. The course of the longest surviving dog is depicted in FIGURE 9. The animal had a normal BUN for four months after operation. At this time azathioprine therapy was discontinued. Azotemia has since slowly developed. The animal's weight has declined from $10 \mathrm{~kg}$. to $8.8 \mathrm{~kg}$. since operation.

Histologic studies revealed depletion of the white pulp and intraparenchymal hemorrhage in the dogs dying within the first 20 days. In the animal's living chronically, there was, however, good preservation of splenic architecture. An example obtained seven months after operation is shown in FIGURE 10, along with the companion kidney section. The kidney appeared to be the site of chronic rejection, with numerous islands of mononuclear cells. The splenic architecture 


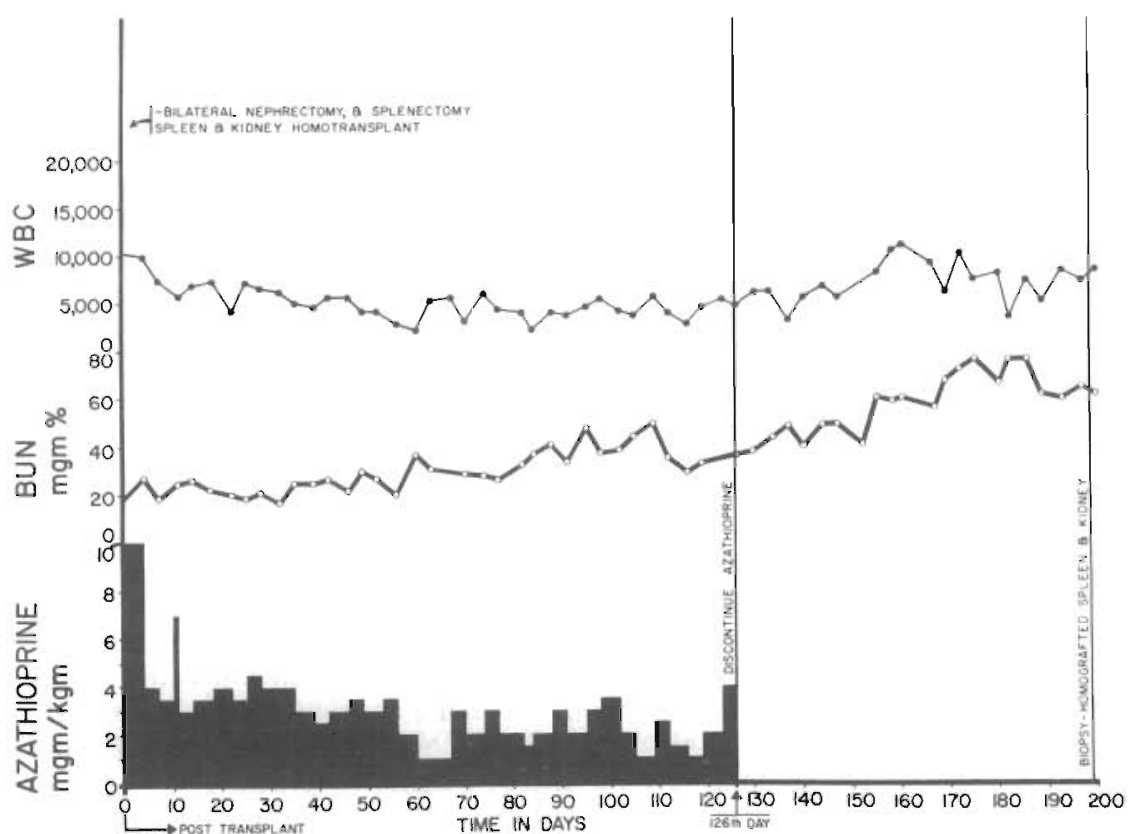

FIgure 9. Course of animal No. KSI-8. Following spleen and kidney homotransplantation, azathioprine was used as immunosuppressive therapy in this animal for 126 days postoperatively. During the postoperative course, splenic function was inferted from continued activity of the kidney. This was confirmed seven months postoperatively by open biopsy at which time both kidney and spleen were normal grossly. Note the progressive slow rise in BUN after discontinuing azathioprine.

is recognizable as such, with numerous Malpighian corpuscles, some of which contain germinal centers. The spleen at the time of biopsy was approximately two-thirds normal size and had a perfectly normal contour. Similar findings were, noted in animals living for one month or longer, but which died for a variety of reasons or were sacrificed.

\section{Clinical Splenic Homotransplantation in Patients with Cancer}

The essential purpose of the splenic whole-organ transplantation in this study was to direct a graft-versus-host reaction against the tumor, a concept similar to that recently propounded by Woodruff. ${ }^{2}$ In an effort to give increased selectivity to such a reaction, the splenic donors were presensitized with tumor cells from the eventual recipient. In this group, each recipient received a spleen from another patient who also had terminal malignancy (TABLE 2). The prospective donor was injected subcutaneously 12 to 56 days before transplantation, with tumor cells from the eventual recipient. The tumor cells were rendered nonviable in a glass emulsifier and the inoculum was then suspended in a mixture of complete $(0.5$ ml.) and incomplete $(3.5 \mathrm{ml}$.) Freund's adjuvant. A booster dose of the same suspension was given 3 to 21 days preoperatively with a mixture of $2 \mathrm{cc}$. com- 


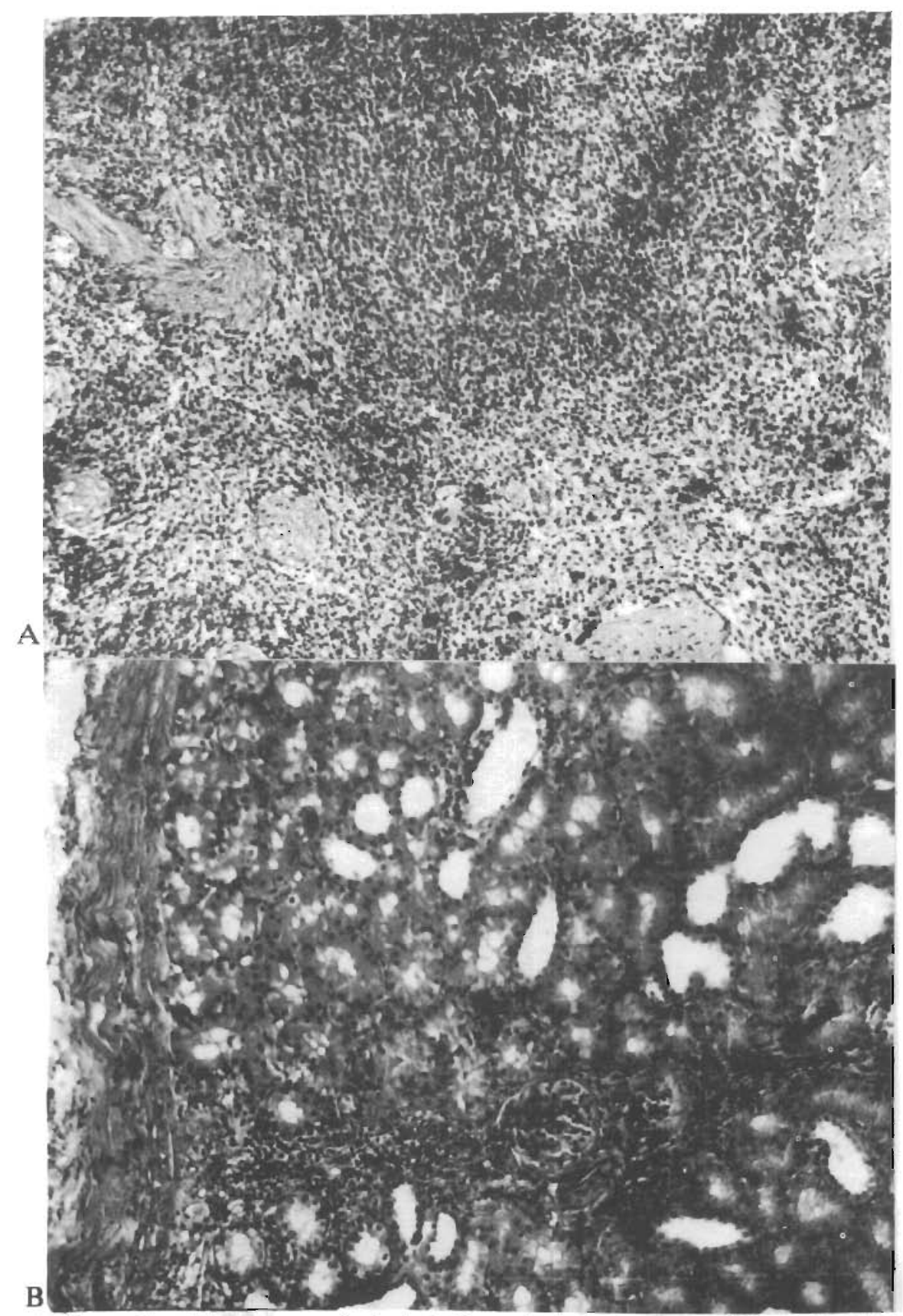

FIGURE 10a. Photomicrograph of splenic biopsy obtained at seven months from dog whose course is depicted in FlGURE 9. Note the preservation of architecture and the persistence of normal white pulp (hematoxylin and eosin, $\times 80$ )

FIGURE $10 b$. Companion biopsy specimen of kidney removed at seven months. The histologic picture is interpreted as showing evidence of chronic rejection, although pyelonephritis cannot be excluded (hematoxylin and eosin, $\times 80$ ). 


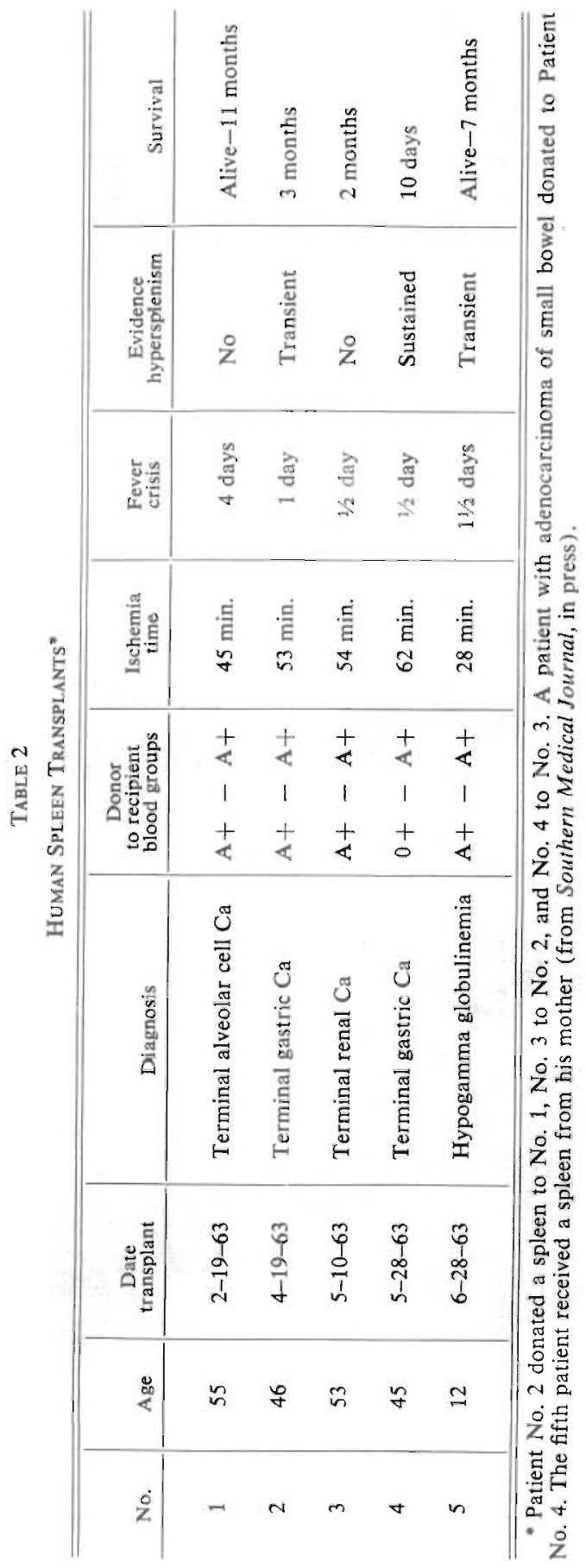




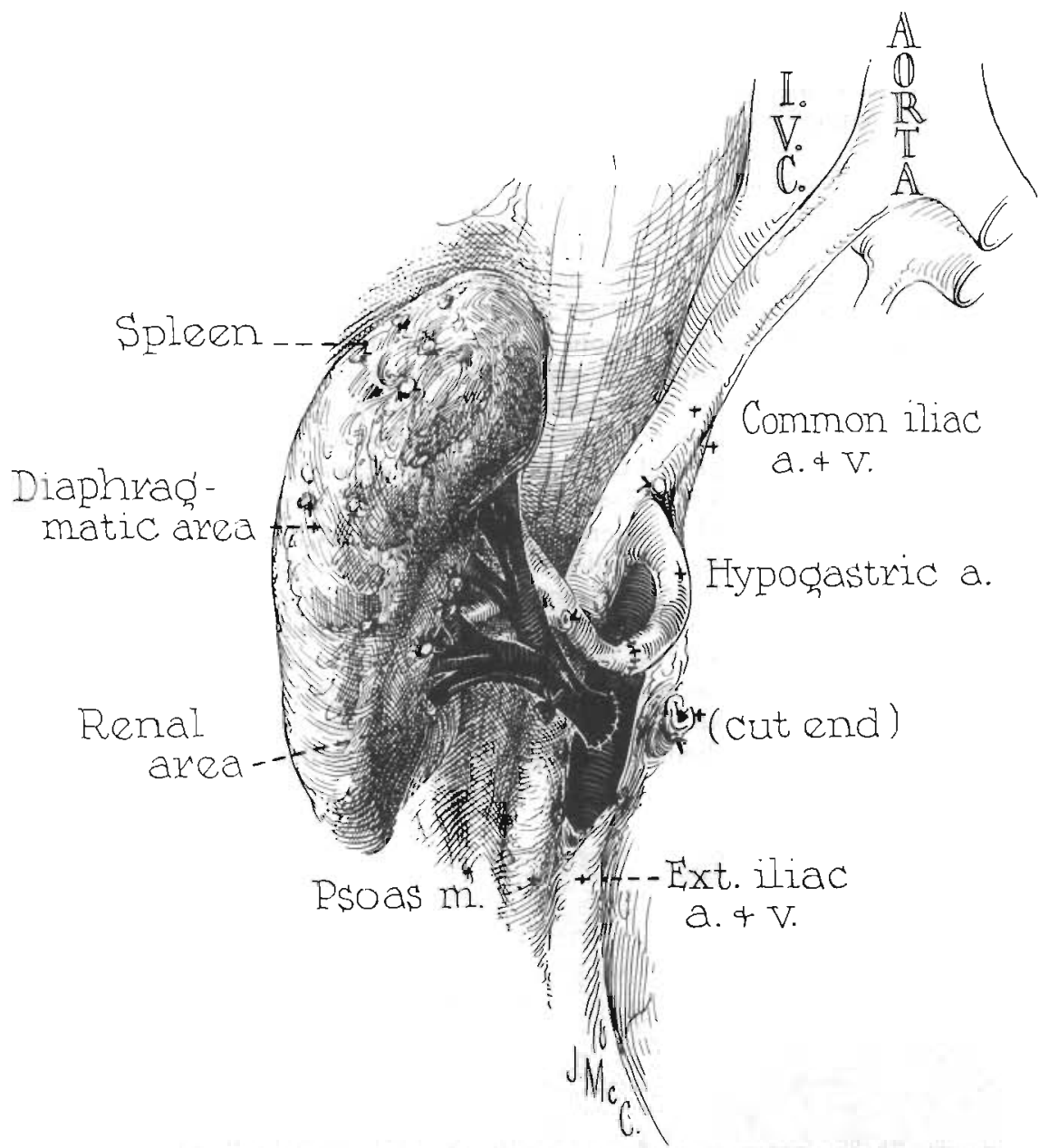

FIGURE 11. Technique used for placing human splenic homograft. The spleen has been rotated so that the posterior surface is now anterior.

plete and $2 \mathrm{cc}$. incomplete adjuvant. The spleens were thus exposed to recipient antigens in advance, but the recipients had no prior exposure to the homografts. The first patient did not have removal of his own spleen and the final patient did not receive a transplant.

The spleen was removed from the donor through a thoracoabdominal incision and transplanted to the right iliac fossa of the recipient as shown in FIGURE 11. In all cases the ischemic interval for the homograft was 62 minutes or less. Protection against the effect of anoxia was provided by perfusion with chilled lactated Ringer's solution. Immunosuppressive therapy with azathioprine was started several days before operation and continued indefinitely thereafter. Prednisone and actinomycin $C$ were added when the diagnosis of rejection was made.

Effect upon tumor growth. The types of donor and recipient malignancies are indicated in TABLE 2. In no case was cessation or regression of tumor growth 
noted. The patients died after ten days, two months, and three months-one patient still being alive 11 months after the operation. The last case had multiple alveolar cell carcinomas and remains in fair health, although radiographic progression of the pulmonary lesions has occurred.

Evidence of hypersplenism. Florid hypersplenism occurred in Case 4-a patient with disseminated gastric carcinoma. The donor was of $\mathrm{O}+$ blood type and recipient $\mathrm{A}+$. Within 12 hours of operation the patient developed hyperpyrexia and hemolytic jaundice. Red cell half-life was too short to be accurately measured, being less than 12 hours. He also developed profound leukopenia (less than 1,000 ) and thrombocytopenia (less than 20,000). On the 10th postoperative day, while being taken to the operating room for removal of the spleen, he aspirated and died. The spleen was enormously congested, weighing 1,500 grams. Histologically, there were remnants of recognizable white pulp in a sea of intraparenchymal hemorrhage. There was no evidence of erythrophagocytosis.

In another patient (Case 2), red cell half-life was transiently depressed from a control of 25 days to 9 days, the shortening occurring 22 days after operation. Subsequently, the patient died of extension of the malignant process. The spleen at autopsy appeared to be grossly well-preserved. However, there was extensive destruction within the organ with only remnants of white pulp. The predominant finding was extensive fibrosis (FIGURE 12). A third patient had no alteration in red cell survival time and died two months after operation of widespread renal cell carcinoma. A similar general destruction of the homograft was evident with large areas of necrosis (FIGURE 13). The fourth patient (Case 1) is alive one year after operation. The splenic homograft appeared not to change in size for eight

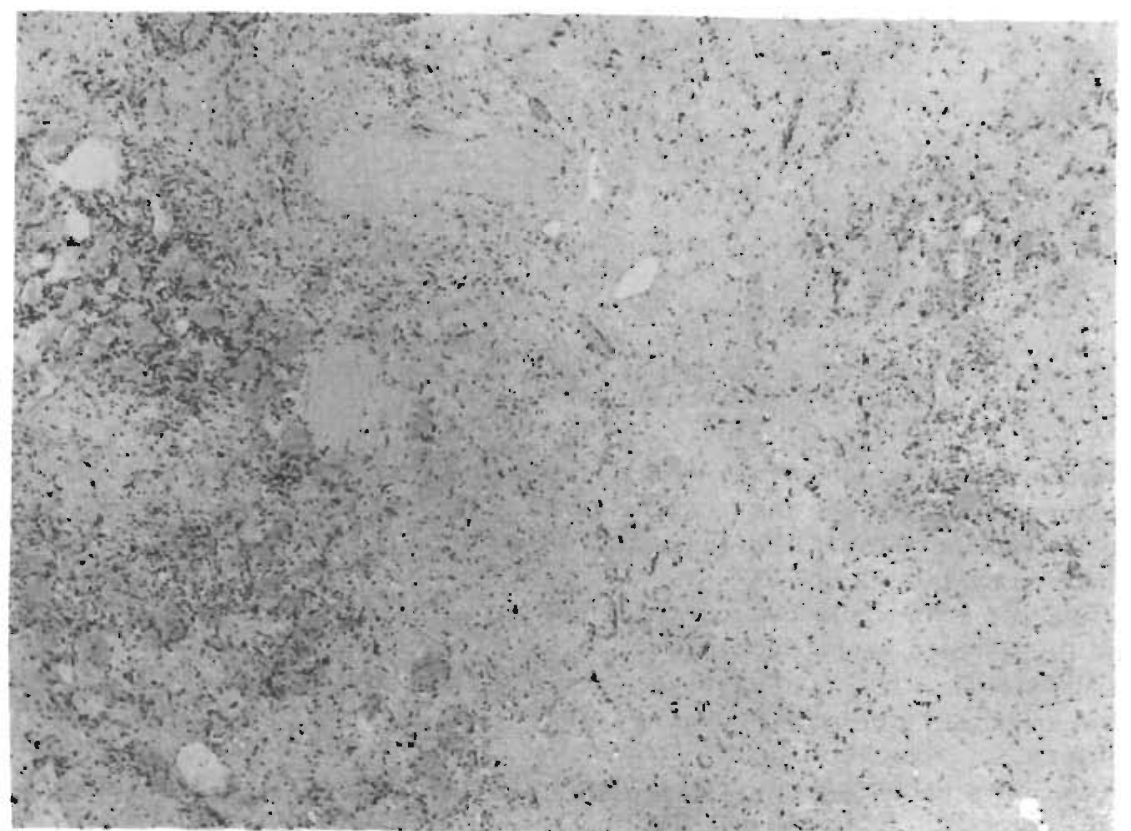

Figure 12. Photomicrograph of spleen obtained at autopsy in Case 2 (TABle 2). Note the extensive fibrosis throughout (hematoxylin and eosin, $\times 80$ ). 


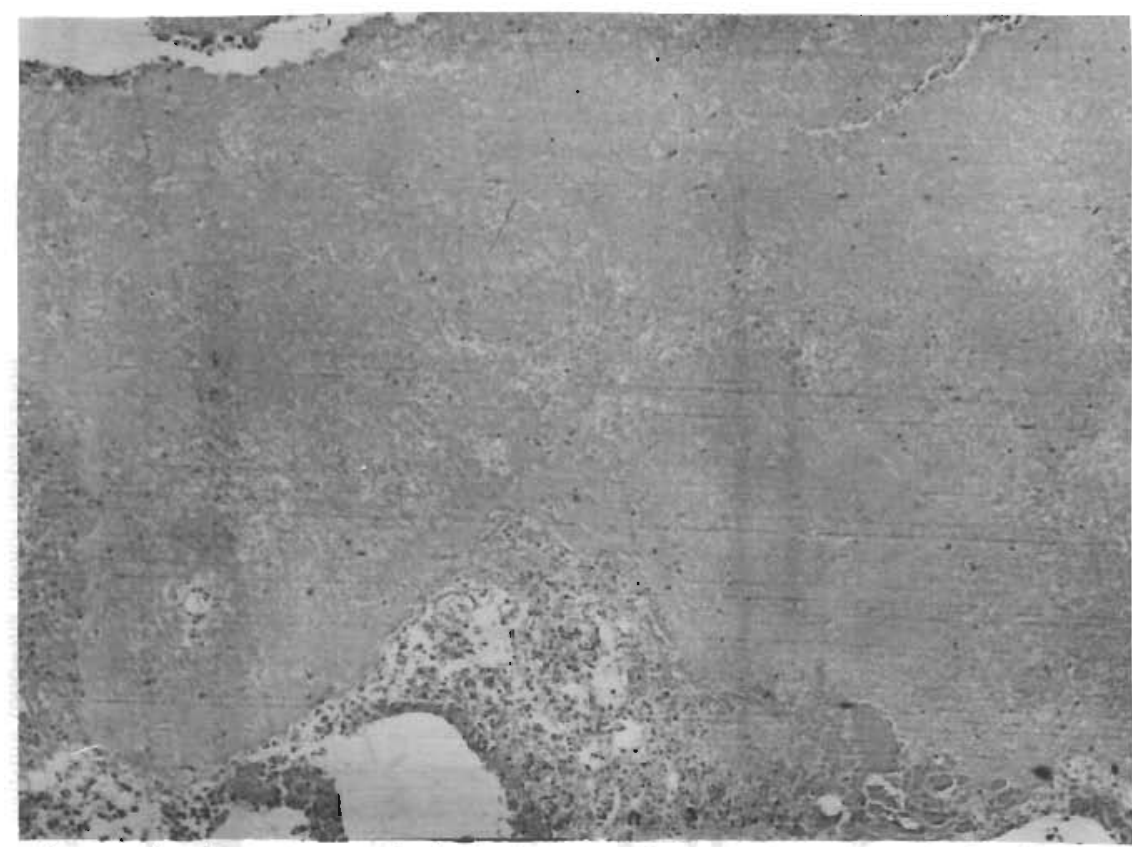

Figure 13. Photomicrograph of splenic homograft obtained at autopsy in Case 3 (tABle 2). Note the widespread necrosis with complete loss of architecture (hematoxylin and eosin, $\times 80)$.

months, but has diminished considerably more recently. It is planned to remove maintenance azathioprine therapy.

Diagnosis of rejection of splenic homograft. One of the great difficulties in treating patients with splenic homografts is the fact that it is a functionally silent organ. Two findings, however, appeared to be relatively characteristic. First, at some time in the postoperative course, all four patients developed hyperpyrexia with fevers to as high as $106^{\circ} \mathrm{F}$. Concomitantly, exquisite wound tenderness developed in each instance, usually with so much edema and induration that wound infection was suspected in each case. The addition of 100 to $200 \mathrm{mg}$. prednisone per day resulted in prompt resolution of the fever.

\section{Splenic Homotransplantation for Hypogammaglobulinemia}

The purpose of this operation was to provide an immunologically competent organ in a patient with a specific immunologic deficiency, a concept previously tested by Good and his associates, ${ }^{3}$ using free lymph node homografts. The possibility of obtaining long-term survival with hypogammaglobulinemia appeared to be increased by the previous demonstration ${ }^{3}$ that the rejection process was greatly mitigated in victims of this disorder. A report of the case follows:

R. H. A 12-year-old white male was first seen at the Colorado General Hospital in May 1962, with bilateral lower lobe bronchiectasis. A diagnosis of congenital sex linked hypogammaglobulinemia had previously been established.

The patient's capacity to reject a homograft was tested in August 1962, by 


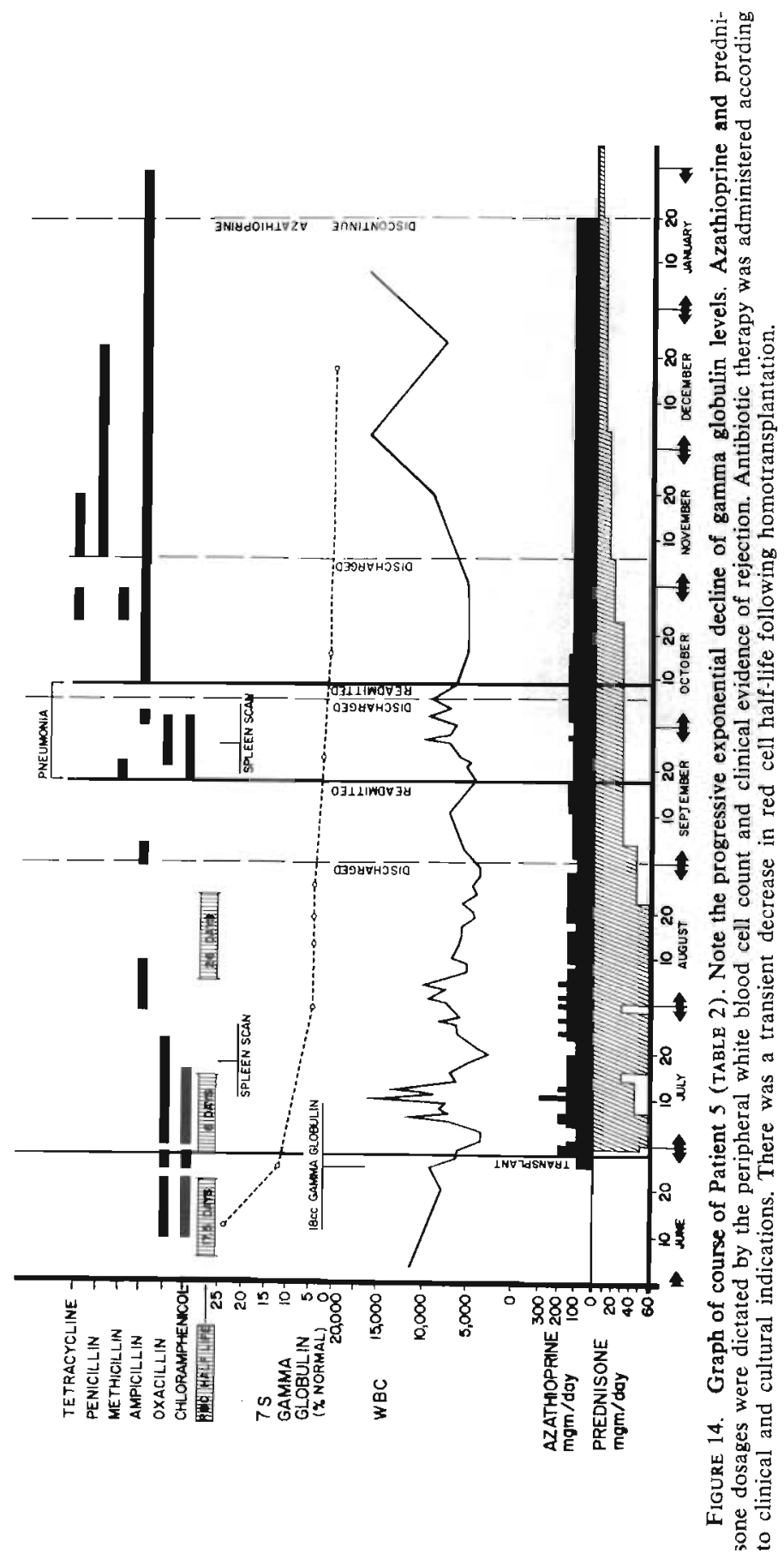




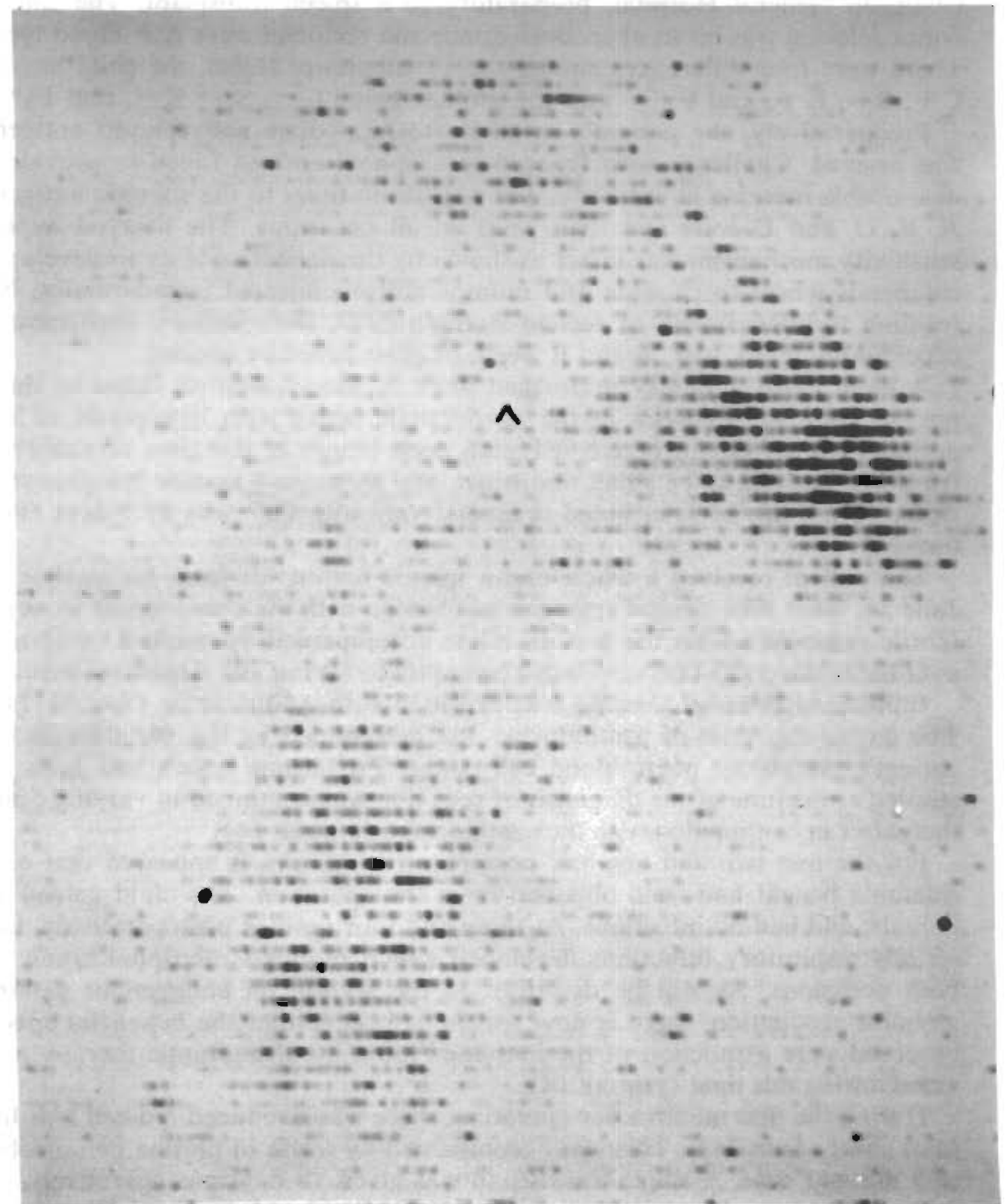

Figure 15. Reproduction of radioisotope spleen scan obtained in Case 5 (TABle 2) ono month postoperatively. Activity is greatest over the patient's own spleen (right upper) as contrasted to the homograft (left lower portion of Figure). 
the transfer of a full thickness skin graft from his mother to his abdomen. After a period of initial viability, the graft sloughed by the 13th day. He was then transferred to a pulmonary disease hospital where intensive medical therapy was carried out for his bronchiectasis for the next nine months. During this period, injections of gamma globulin were administered frequently (FIGURE 14).

When maximum hospital benefit had been obtained, he was readmitted to Colorado General Hospital, preparatory to a spleen transplant. The spleen donor selected was his mother. Both donor and recipient were $\mathrm{A}+$ blood type. There were four differences among the 15 subgroups tested, the child having $\mathrm{C}+, \mathrm{S}+, \mathrm{K}+$, and $\mathrm{Fy}^{2}-$ and the mother being $\mathrm{C}-, \mathrm{S}-, \mathrm{K}-$, and $\mathrm{Fy}^{\mathrm{a}}{ }^{-}$.

Preoperatively, the patient's reactivity to immediate and delayed antigens was assayed. Challenge with typhoid-paratyphoid antigen failed to provide a measurable increase in antibody. The agglutinin titers to the somatic antigens A, B, C, and D were less than 1:20 on all occasions. The delayed hypersensitivity mechanism was intact as shown by the patient's ability to develop a cutaneous wheal to candida and mumps antigen injected intradermally. No reaction to intermediate or second strength PPD, histoplasmin, blastomycin, coccidiodin, mold, tree, A and B weed, or grass could be elicited.

A bone marrow biopsy performed prior to transplantation failed to show plasma cells. Hyperplasia in the erythrocytic series with hypoplasia of the granulocytic series was noted. A lymph node biopsy at this time revealed the lymphoid nodules to be small, indistinct, and to contain mature lymphocytes. Red cell half-life as determined preoperatively with $\mathrm{Cr}^{51}$ was 17.5 days (FIGURE 14).

The patient received a whole-organ splenic homograft from his mother on June 28,1963 . The clinical response was benign with the exception of an acute febrile response within the first 48 hours accompanied by marked tenderness over the homograft. This responded promptly to $60 \mathrm{mg}$. per day of prednisone.

Immunosuppressive therapy was provided with azathioprine (FIGURE 14). The day-to-day dose of azathioprine was determined by the variation in the patient's peripheral white blood cell count. Prednisone which had been instituted at the time of the diagnosis of rejection was continued in varying doses thereafter in conjunction with the azathioprine (FIGURE 14).

For the first two and one-half postoperative months, it appeared that considerable benefit had been obtained from the operation. The child gained 35 pounds, and had no infections. At three and four months postoperatively, two serious respiratory infections developed which required rehospitalization on both occasions. As will be described in the section on endogenous gamma globulin production, there is now reason to believe that the beneficial effects observed were a function of the increased intensity of antibiotic therapy provided during this time (FIGURE 14).

During the first month after operation, there was a reduced red cell half-life to as short as six days. This was accompanied by a rise in plasma hemoglobin to $5 \mathrm{mg}$. per cent. A single transfusion was given 18 days postoperatively.

Radioisotope spleen scans using Hg-197 labeled bromomercurihydroxypropane ${ }^{4,5}$ obtained one month after operation showed sequestration of radioactivity both in the transplanted and in the child's own spleen, the concentration being less in the homograft (FIGURE 15). After three months, radioactivity in the homograft had sharply diminished and the presence of a selective concentration could not be stated with certainty (FIGURE 16).

* These tests were performed by Dr. W. E. C. Wilson and Dr, C. Kirkpatrick 


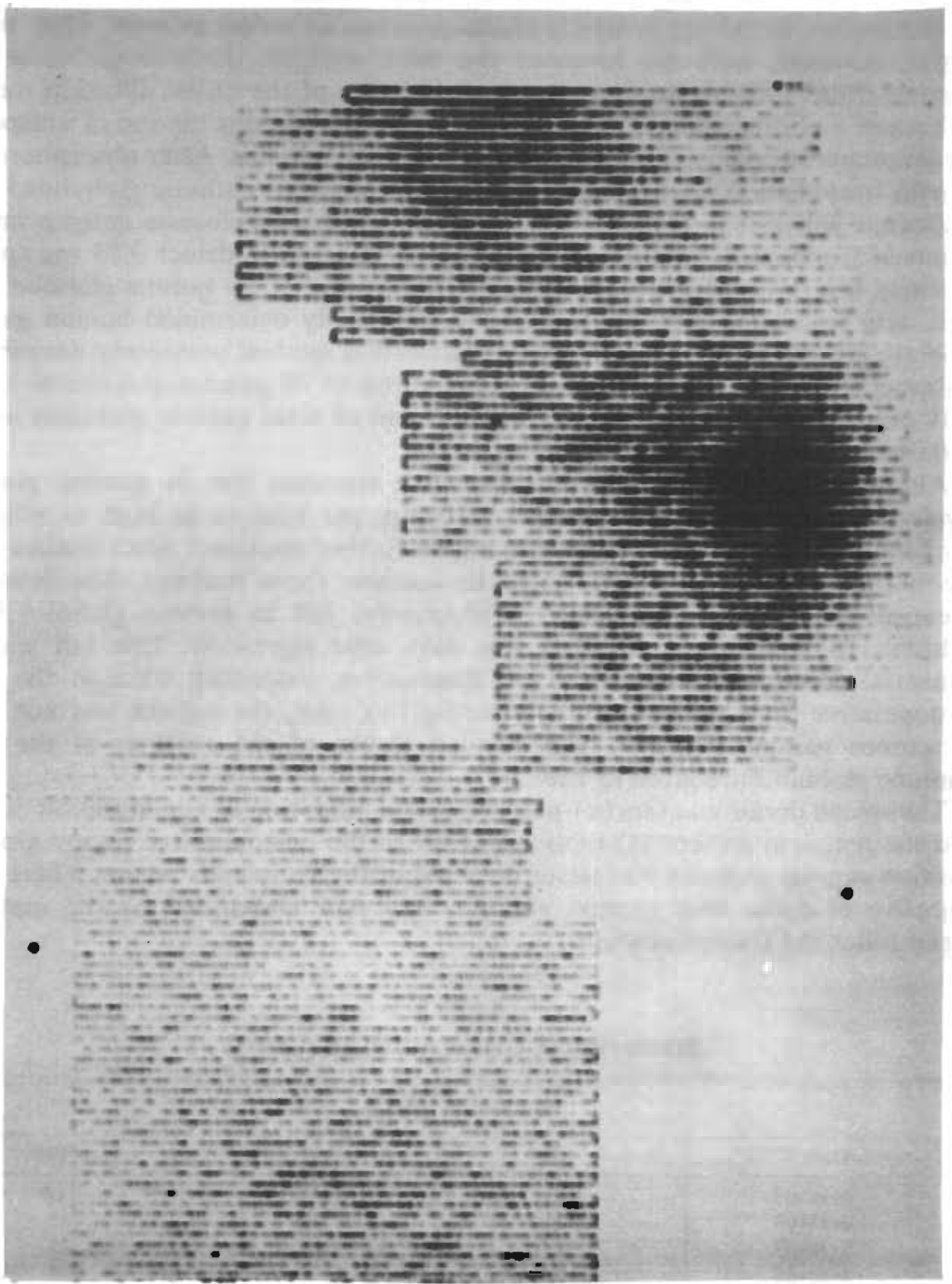

FIGURE 16. Radioactive spleen scan obtained three months postoperatively in Case 5 (TABLE 2). No appreciable concentration of activity is noted over the homografted spleen. 
Studies of immunologic reactivity. Repeat studies with typhoid-paratyphoid antigens were done four and six weeks postoperatively. There was no demonstrable rise in antibody titers to any of the antigens. A lymph node biopsy at six weeks again showed lymphoid hypoplasia with absence of plasma cells. Bone marrow biopsy postoperatively showed no change from that observed preoperatively.

Gamma globulin studies. Gamma globulin levels were studied by a variety of techinques, including biweekly electrophoresis of serum protein. Most meaningful, however, were the levels of the three separate immune globulins (7S, gamma $a_{1 a}$, and $19 \mathrm{~S}$ ) determined by a modification of the radial diffusion method of Tomasi and Ziegelbaum. ${ }^{6}$ The principle of this method is the use of unispecific serum prepared against the three normal immune globulins. After absorption with Papain fragments A-C, which are common to all three immune globulins, ${ }^{7}$ each antiserum will give a precipitation band only with homologous antigen on immunoelectrophoresis. ${ }^{8}$ With this method, it is possible to detect $0.05 \mathrm{mg} . / \mathrm{ml}$. of gamma $_{1 \mathrm{a}}$ and $19 \mathrm{~S}$ gamma globulin and $0.03 \mathrm{mg} . / \mathrm{ml}$. of $7 \mathrm{~S}$ gamma globulin. Sera were also tested for their content of the genetically determined human gamma globulin groups ${ }^{9}$ by the inhibition of agglutination method previously described. ${ }^{10}$ This method permits detection of concentrations of $7 \mathrm{~S}$ gamma globulin as low as $0.01 \mathrm{mg} . / \mathrm{ml}$. by $\mathrm{gm}$. (a) and (b) typing, ${ }^{9}$ and of total gamma globulins as low as 0.015 to $0.20 \mathrm{mg} . / \mathrm{ml}$. by Inv (a) typing.

Although paper electrophoresis showed a transient rise in gamma globulin levels from the preoperative value of $80 \mathrm{mg}$. per cent to as high as $600 \mathrm{mg}$. per cent, results with this method will not be further discussed, since studies using the immunochemical method failed to confirm these findings. The immunochemical technique demonstrated a progressive fall in gamma globulin levels (FIGURE 14), beginning within a few days after operation. This fall was exponential throughout the period of observation, extending through the sixth postoperative month (FIGURE 14). During this time, the patient was not given exogenous gamma globulin. The detailed results of the analyses of the three immune globulins are given in TABLE 3 .

The spleen donor was $\mathrm{Gm}(\mathrm{x})$ positive by the inhibition of agglutination method and the recipient patient $(\mathrm{Gm}(\mathrm{x})$ negative. In the postoperative period $\mathrm{Gm}(\mathrm{x})$, positive gamma globulin was never detected in the recipient's serum. There is no objective evidence that gamma globulin was ever elaborated by the maternal organ following transplantation.

TABLE 3

Serum Immune Globulin Levels (Case 5)

\begin{tabular}{|c|c|c|c|}
\hline \multicolumn{4}{|c|}{ Per cent of normal } \\
\hline Date & $7 S$ & $\gamma 1 \mathrm{~A}$ & $19 \mathrm{~S}$ \\
\hline $\begin{array}{r}6-12-63 \\
6-25-63 \\
7-30-63 \\
8-13-63 \\
8-19-63 \\
8-26-63 \\
9-23-63 \\
10-16-63 \\
12-18-63\end{array}$ & $\begin{array}{c}24 \\
12 \\
4.6 \\
4.6 \\
4.6 \\
4.6 \\
2.4 \\
1 \\
<1\end{array}$ & $\begin{array}{l}12 \\
12 \\
2.0 \\
2.5 \\
0^{*} \\
0 \\
0 \\
0 \\
0\end{array}$ & $\begin{array}{l}0^{*} \\
0 \\
0 \\
0 \\
0 \\
0 \\
0 \\
0 \\
0\end{array}$ \\
\hline
\end{tabular}

* Less than three per cent of normal level (less than $0.3 \mathrm{mg}$. per cent). 


\section{Discussion}

The animal and clinical experience described provides considerable information concerning the effectiveness of immunosuppressive therapy in potentiating splenic homograft survival. It seems clear that chronically viable spleen tissue can be maintained, although such successfully managed cases are in the minority. One of the principal deterrents to consistent success is the inability to monitor function, since the spleen is not a vital organ and its activities cannot be followed with the same precision as other organs, such as the kidney. Indeed, in dogs treated with splenic homotransplantation alone, prolonged survival was never achieved, nor was it even attempted, inasmuch as the majority of dogs receiving only this organ were sacrificed.

The use of the kidney as an indicator organ eliminated the difficulty of relating function to therapy. Using this approach, viable splenorenal homografts were maintained for as long as seven months. It might be reasoned that the concomitant use of the two organs could make the problem of immunosuppression more easily manageable because of the known greater ease of retaining alien tissue in the presence of azotemia. However, in the animals followed for the longest periods, uremia was not prominent.

In the animals receiving double organs, there was evidence that the splenic tissue was more susceptible to immunologic attack than the kidney, since as was described, the spleen was frequently far more disorganized architecturally than the kidney which had been obtained from the same donor. An alternative explanation for this observation might be that the spleen has a greater antigenicity, although it would be expected that the antibody response would be equally directed to both the splenic and renal targets.

Despite the difficulty in defining the events transpiring within the functionally silent splenic homografts, there were at least two findings which were of practical value. As evidence of rejection, the patients developed marked hyperpyrexia, as well as tenderness in the wound site. The addition of prednisone to the preexisting therapy with azathioprine resulted in prompt reversal of these findings. Such crude indicators of a rejection episode are, however, inadequate for the dayto-day planning of immunosuppressive therapy. It is probable that other laboratory determinations measuring specific functional attributes of the transplant will be required before further progress in delineating effective therapeutic regimens will be possible.

A second important group of observations relate to the potential harmful effects that such a lymphoendothelial graft might have on the host. Such observations should have collateral application when bone marrow or other lymphoid transplants are employed in the future. The most consistent injurious effect was the development of a hemolytic process, which was greatly accentuated under experimental circumstances in which there was advance selective host injury as with total-body irradiation. Although hemolysis was observed in untreated animals receiving splenic homografts, and occasionally in animals treated with azathioprine, it proved to be an explosive disease process only in those dogs treated with total-body irradiation. The nature of the hemolytic process is not yet clear. Fiscus and his associates, ${ }^{11}$ on the basis of similar observations, concluded that a graftversus-host mechanism with hypersplenism was responsible. As will be discussed subsequently, it was impossible to correlate this presumed pathologic splenic activity with the more normal processes of splenic antibody formation. Consequently, an alternative explanation may be necessary. It was noted in the animals, as well as in the three human homografts recovered at autopsy, that intra- 
parenchymal splenic hemorrhage was a prominent feature of rejection, an observation previously made by Fisher and his associates. ${ }^{12}$ It seems possible that the sequestration of red cells in the homograft, and the hemolysis which has been observed were features more of repudiation of the splenic homograft than evidence of its inherent ability to destroy host red cells by an immunologic mechanism.

It is of interest that long-term splenic homografts have been possible in dogs without evidence of chronic graft-versus-host activity. That a graft-versus-host reaction could occur was strongly suggested by the pathologic studies in dogs of Dammin and his associates, ${ }^{13}$ although their findings were at variance with those reported using similar experimental protocols by Fisher et al. ${ }^{12}$ In any case, it has been demonstrated that chronic survival of splenic homografts is possible for as long as seven months in dogs without the wasting characteristics of "runt" or "secondary" disease. The avoidance of a generalized graft-versus-host reaction may have been due to the therapy with azathioprine, a drug which would suppress the immunologic activity of the homograft: as well as the host.

It has already been mentioned that the only function of the splenic homograft which could be demonstrated either in dogs or in patients was accelerated red blood cell destruction. It has further been emphasized that the explanation for this finding may or may not be a function of the transplanted organ's immunologic capacity. In the patient with hypogammaglobulinemia, it was disheartening to note that gamma globulin production by the transplanted tissue did not apparently occur. The uniquely complete failure of gamma globulin production was quite unexpected in view of Good's demonstration that the lymph node homografts resulted in at least a transient rise in gamma globulin. ${ }^{3}$ The possibility must be considered that the immunosuppressive regimen employed to prevent rejection of the transplanted tissue may have also neutralized its ability to elaborate antibodies. Rifkind and his associate ${ }^{14}$ have recently demonstrated that some patients receiving renal homografts with a similar pharmacologic regimen developed profound depression of serum gamma globulin. A similar explanation may account for the ineffectiveness of splenic homotransplantation in the treatment of patients with malignant neoplasms, since the antibody potential of the transplanted tissue may have been obtunded as much or more than that of the host.

\section{Summary}

A series of canine splenic homografts was performed. Animals pretreated with total-body irradiation showed markedly shortened red cell half-life and sharp drops in hematocrit with no potentiation of homograft survival. Those dogs treated with azathioprine had no change in red cell half-life, hematocrit changes were much less than in the irradiated animals, and homograft survival was increased as judged by pathologic studies.

In another series of animals, simultaneous renal and splenic homografts were performed to bilaterally nephrectomized dogs. Function of both transplanted organs was inferred from the behavior of the renal homograft. Control animals receiving no therapy showed a somewhat delayed rejection. Those dogs treated with total-body irradiation frequently developed severe hemolytic anemia and graft survival was less than in untreated animals. Both the spleen and the kidney appeared to be particularly susceptible to the rejection reaction in this series, and of the two organs, the spleen appeared to be more damaged than the kidney. When azathioprine was used as the immunosuppressive agent, survival of both renal and splenic homografts was obtained to as long as seven and one-half 
months. Anemia was not noted in these animals after the first month and gross and microscopic examination at seven months revealed both organs to be viable. No evidence of secondary disease was observed in these dogs. In one animal, azathioprine was discontinued after 120 days. He remains alive, three and onehalf months later.

In addition, whole-organ spleen homotransplantation was carried out in five patients. In four instances the purpose was to provide a continuous endogenous source of antibody against a malignant tumor. In the fifth case, it was hoped that the homograft would supply the immunologic deficiency in a child with congenital sex linked hypogammaglobulinemia.

The clinical experience was disappointing. In the patients with tumor, no alteration of the progression of the disease was obtained. In one patient of $\mathrm{A}+$ blood type, who received a spleen from an $\mathrm{O}+$ donor, severe hypersplenism developed shortly after transplantation. One patient is alive 11 months postoperatively with radiographic evidence of progression of his alveolar cell carcinoma. In the child with hypogammaglobulinemia, evidence for production of gamma globulin by the homografted spleen could not be obtained by a variety of techniques.

\section{References}

1. Kountz, S. L. \& R. CoHn. 1962. Prolonged survival of a renal homograft by simultaneous splenectomy and splenic homotransplantation. Surg. Forum 13: 59.

2. Woodruff, M. F. A. \& B. Nolan. 1963. Preliminary observations on treatment of advanced cancer by injection of allogeneic spleen cells. Lancet $2: 425$.

3. GOOD, R. A., R. L. VARCO, J. B. AUST \& S. J. ZAK, 1957. Transplantation studies in patients with agammaglobulinemia. Ann. N. Y. Acad. Sci. 64; 882

4. Wagner, JR., H. N. 1962. Radioisotope scanning of the spleen. Proc. Symp. Med. Div. Oak Ridge Inst. Nucl. Stud. Prog. Med. Radioisotope Scanning : 468-483.

5. Wagner, JR., H. N., J. G. MCAfee, I. M. Wiener, M. Iho, J. Martinez \& P. C. Winston, JR. 1963. The use of $\mathrm{Hg}-203$ labeled bromomercurihydroxypropane (BMHP) in radioisotopes scanning of the spleen. J. Nucl. Med. 4: 190.

6. Tomasi, T. B. \& S. Zieglbaum, 1963. The selective occurrence of $\gamma 1 \mathrm{~A}$ globulins in certain body fluids. J. Clin. Invest. 42: 1552 .

7. Franklin, E. C., H. H. Fudenderg, M. Meltzer \& D. Stanworth. 1962. The structural basis for genetic variations of normal human $\gamma$-globulins. Proc. Natl. Acad. Sci. (U.S.) 48: 914

8. Heremans, J. F. 1960, Les Globulines Sériques du Système Gamma. Arseia, Sa. Brussels, Belgium.

9. FUDENBERG, H. 1963. The hereditary gamma globulin groups: Interpretations and extension. In Progress in Allergy. B. Waksman, Ed. 7. Verlag S. Kargar A.-G. Basel, Switzerland.

10. Fudengerg, H, H. \& H. Kunkel. 1961. Specificity of the reaction between rheumatoid factors and gamma globulin. J. Exptl. Med. 114: 257.

11. Fiscus, W. G., J. J. Trentin, V. P. Collins, D. G. Fuller \& G. L. Jordan. 1963. Effect of spleen homotransplantation in animals subjected to sublethal doses of total body irradiation. Surg. Forum 14: 182 .

12. Fisher, B., S. H. LeE \& E. R. Fisher. 1961. Observations concerning spleen homotransplantation in normal and irradiated animals. Surg. Gynecol. Obstet. 112: 455.

13. Dammin, G. J., H. B. Wheeler, A. C. W. Montague, J. B. Dealy, JR., J. B. Greenberg \& F. D. MoorE. 1962. The splenic homograft: Its course in the unmodified and modified canine recipient. Ann. N. Y. Acad. Sci. 99: 861.

14. Rifkind, D., T. L. Marchioro, W. R. Waddell \& T. E. STarzl. Infectious diseases associated with renal homotransplantation. I. Incidence, types and predisposing factors. J. Am. Med. Assoc. (in press). 